\title{
Incidence of Ophthalmic Start-Ups
}

William C. Stewart*, Shilla Marie Hernandez, Jeanette A. Stewart and Lindsay A. Nelson

PRN Pharma Farm, LLC, Las Vegas, NV1, USA

*Corresponding author: William C. Stewart, PRN Pharma Farm, LLC, Las Vegas, NV1, USA, E-mail: info@prnorb.com

Received date: April 25, 2018; Accepted date: May 14, 2018; Published date: May 24, 2018

Copyright: (C) 2018 Stewart WC, et al. This is an open-access article distributed under the terms of the Creative Commons Attribution License, which permits unrestricted use, distribution, and reproduction in any medium, provided the original author and source are credited.

\begin{abstract}
Purpose: To evaluate the incidence of start-up company formation associated with new molecules or new indications for older medicines within 5 years of their description in ophthalmic peer-reviewed literature.

Methods: A retrospective, observational review of new ophthalmic pharmaceutical compounds or new indications of older products appearing on PubMed between June 01, 2010 and December 31, 2011.

Results: Included in this study were new compounds $(n=21)$ or older compounds with a new indication ( $n=28)$. The most frequent indications were: anti-infectives $(n=7)$, glaucoma $(n=5)$, and anti-retinal neovascularization $(n=4)$. No new ophthalmic companies were founded by the original author(s) for the originally described indication (0/49) within 5 years of publication. In contrast, 2 ophthalmic companies for a different ocular indication than originally described, and 2 outside ophthalmology for a systemic indication, were formed around 4 compounds. Evidence of at least some further work towards developing a new company past the initial publication was noted in 15 total cases and included: grants $(n=4)$, press releases $(n=3)$, filing a patent $(n=15)$ and obtaining an issued patent $(n=8)$.
\end{abstract}

Conclusions: There is a low progression rate from new ocular compounds described in the medical literature to company start-up formation within 5 years that might lead ultimately to commercialization of a new medication.

Keywords: Ophthalmology; Ophthalmic; Ocular; Start-up; Development

\section{Introduction}

New potential medications to treat ophthalmic patients often are discovered by professors at university laboratories. Unfortunately, developing a nascent discovery into a new company to commercialize a potential therapeutic product is time and cost intensive. Further, most professors are not trained in business development or working as a CEO. To complicate matters further, universities vary in their capacity to help develop new intellectual property derived from the school's laboratories [1].

Unfortunately, little information exists in the medical or popular literature which explores the success of developing a new ophthalmic company based on findings discovered in university laboratories. The purpose of this article is to evaluate the incidence of start-up company formation associated with new molecules or new indications for older medicines within 5 years of their description in the ophthalmic peerreviewed literature.

\section{Materials and Methods}

The study design was a retrospective, observational review of new ophthalmic pharmaceutical compounds or new indications of older products. Articles that appeared in PubMed (http:// www.ncbi.nlm.nih.gov/pubmed) between June 01, 2010 and December 31, 2011 were collected. Due to the non-interventional, non-clinical participant study design of this research Institutional Review Board/ Ethics Committee approval was not required. Medical devices, stem cells, delivery systems that did not alter the pharmacologic efficacy of the molecule itself, compound products, and commercially available herbal products were excluded.

Articles that presented a new ophthalmic pharmaceutical product or an older compound intended for a new indication were included. The following search terms were used in different combinations: new; pharmaceutical; treatment; ophthalmic; novel; potential; ophthalmology; and ocular. The following information was gathered from the PubMed article: corresponding author; ophthalmic product name; classification; indication; geographic location; affiliation and sponsorship. Follow up history of the new medicines (additional scientific articles; press releases; patents; websites; incubator; angel funding; grants) were confirmed using search engines (www.bing.com; www.Google.com; www.ClinicalTrials.gov; www.patents.google.com, www.ncbi.nlm.nih.gov/pubmed and www.sbir.gov).

\section{Results}

Included in this study were new compounds $(\mathrm{n}=21)$ or older compounds with a new indication $(n=28)$ that were described in a peer-reviewed article published between July 2010 and December 2011 (total=49). No compounds that met the inclusion criteria were excluded.

The leading authors were located at a university $(\mathrm{n}=48)$ or a private institution $(\mathrm{n}=1)$. In total, 15 were in the United States and 34 nonUnited States, most commonly from the Pacific Rim $(n=16)$. The most frequent indications were: anti-infectives $(n=7)$, glaucoma $(n=5)$, and anti-retinal neovascularization $(n=4)$.

Using publicly available information, no new ophthalmic companies founded by the original author(s) for the originally described 
indication (0/49) within 5 years of publication were identified. In contrast, 2 ophthalmic companies for a different ocular indication than originally described, and 2 outside ophthalmology for a systemic indication, were formed around 4 compounds. Publicly available documents did not indicate that any the original authors or universities were associated with these companies.

Nonetheless, evidence of at least some further work towards developing a new company past the initial publication was noted in 15 total cases and included: grants $(n=4)$, press releases $(n=3)$, filing a patent $(n=15)$ and obtaining an issued patent $(n=8)$. However, in 11 of these 15 patent filings, they were submitted by someone other than the authors of the original publication. Further, of the original 8 issued patents, 4 were from someone other than the original authors.

\section{Discussion and \onclusion}

Our findings indicate that of the 49 new ophthalmic molecules or older medicines described for a new indication and published in the peer-reviewed literature between 2010 to 2011 were not associated with a new ophthalmic company formation within 5 years of followup. However, 4 companies were formed around the original compound for a different indication, 2 being ophthalmic. Evidence of further development of the new drug (mostly grant activity) by different individuals was found in 15 instances of the ophthalmic compounds leading to a start-up company.

These findings raise concern because of the money and time spent by dedicated professors and universities to discover new compounds to treat an ocular disease which in every case in our study came to an end with no apparent benefit for the author or their institution and only 2 potential compounds being developed for ophthalmic patients. Even if the majority of products in early development in a laboratory ultimately provide no clinical value, one might think that some significant minority might possess treatment potential. Venture Capital funds typically accept $2-4 \%$ of applications for funding [2,3]. Accordingly, start-ups then take their compounds to numerous funding sources, greatly expanding their chance for funding success. Recent research has shown $30 \%$ of ophthalmic start-ups will obtain funding to progress their product development [4].

The reasons for the lack of creation of new ophthalmic start-ups from laboratory discoveries, apart from too little clinical value mentioned above, were not clear by the public data found. However, it could be speculated on the following reasons related to the original lead author: first, a lack of time and/or personnel resources; second, a lack of knowledge in how to initiate a start-up company, a very intimidating regulatory burden which is causes a high cost in time and money to bring any product to market and last, a lack of seed funding from the university, angels, or friends and family, to begin a start-up process. In addition, universities vary widely in their ability and interest to create attractive license deals for their professors [5]. Even a well-meaning university may lack the knowledge, experience or resources to effectively help discoveries.

How can one use these findings to help bringing new ocular medicines to market? Our data indicate that a significant blockage exists, from discovery of a potential new medicine to initiation of a start-up that may parallel the dropout rate of new compounds from lead product identification to commercialization [1]. This information might provide a basis to help angels, universities, or government agencies develop methods to assist professors either in seed funding, education, or personnel availability to help them create start-ups that might better supply unmet medical therapeutic needs of ocular patients.

This study suggests that there is a low progression rate from new ocular compounds described in the medical literature to company start-up formation within 5 years that might lead ultimately to commercialization of a new medication. This study is limited by the range of follow up as company formation could have developed afterwards in a few cases. Also, our dependence on public data may not have uncovered very early startup without electronic evidence of existence. More research is needed to further understand the difficulties in creating a pharmaceutical start-up and how these new entrepreneurs can best be assisted.

\section{References}

1. Stewart WC, Stewart JA, Nelson LA (2013) The start-up: From dream to reality. Review Ophthalmol: 62-71.

2. Rao D (2013) Why 99.95\% Of Entrepreneurs Should Stop Wasting Time Seeking Venture Capital. Forbes.com.

3. Mulcahy D (2013) Six Myths About Venture Capitalists. Harvard Business Review.

4. Sharpe RA, Austin JP, Kruft B, Nelson LA, Stewart JA, et al. (2015) Description of ophthalmic pharmaceutical and device start-up companies. Ophthalmic Res 54: 6-9.

5. Kolchinsky P The Entrepreneur's Guide to a Biotech Start-up. 